\title{
Three more semantic serial position functions and a SIMPLE explanation
}

\author{
Matthew R. Kelley • Ian Neath • Aimée M. Surprenant
}

Published online: 21 December 2012

(C) Psychonomic Society, Inc. 2012

\begin{abstract}
There are innumerable demonstrations of serial position functions - with characteristic primacy and recency effects - in episodic tasks, but there are only a handful of such demonstrations in semantic memory tasks, and those demonstrations have used only two types of stimuli. Here, we provide three more examples of serial position functions when recalling from semantic memory. Participants were asked to reconstruct the order of (1) two cartoon theme song lyrics, (2) the seven Harry Potter books, and (3) two sets of movies, and all three demonstrations yielded conventionallooking serial position functions with primacy and recency effects. The data were well-fit by SIMPLE, a local distinctiveness model of memory that was originally designed to account for serial position effects in short- and long-term episodic memory. According to SIMPLE, serial position functions in both episodic and semantic memory tasks arise from the same type of processing: Items that are more separated from their close neighbors in psychological space at the time of recall will be better remembered. We argue that currently available evidence suggests that serial position functions observed when recalling items that are presumably in semantic memory arise because of the same processes as those observed when recalling items that are presumably in episodic memory.
\end{abstract}

Keywords Memory $\cdot$ Memory models $\cdot$ Semantic memory $\cdot$ Serial position effects

\footnotetext{
M. R. Kelley ( $\bowtie)$

Department of Psychology, Lake Forest College,

Lake Forest, IL 60035, USA

e-mail: kelley@lakeforest.edu
}

I. Neath · A. M. Surprenant

Memorial University of Newfoundland, St. John, Canada

I. Neath

e-mail: ineath@mun.ca
In many episodic memory tasks, participants are given a list of to-be-remembered items and are asked to recall the items. A ubiquitous finding is that participants produce a bowshaped serial position function in which they remember the first few items in the series well (the primacy effect) and the last few items in the series well (the recency effect) but have poorer memory for mid-series items. This $\cup$-shaped function has been observed for lists that span milliseconds to weeks (Neath \& Brown, 2006) and has even been noted when opera performances attended over a 25-year period have been recalled (Sehulster, 1989). Therefore, serial position functions have been observed in all kinds of episodic memory tasks, including those thought to tap sensory memory, working memory, short-term memory, long-term memory, and autobiographical memory. In tasks thought to tap semantic memory, however, there are only a handful of examples, and these comprise only two types of stimuli: political figures and lyrics. In this article, we provide three additional demonstrations of semantic serial position functions and consider whether there exists a common explanation for such functions regardless of the time scale or the hypothetical underlying memory system.

Many theorists argue that memory consists of a number of different memory systems, each of which operates according to different rules (e.g., Schacter, Wagner, \& Buckner, 2000; Wang \& Morris, 2010). One well-accepted distinction is between episodic and semantic memory (Tulving, 1972, 1983). Although these two systems are thought to differ in a number of important respects, one key distinction is whether the rememberer is aware of the learning episode. For example, most people know that George Washington was the first president of the United States, but they are unaware of when they learned this and are unaware of any other details from the learning episode. In contrast, when people recall a list of words immediately after hearing them, they are fully aware of the episode in which the target items were experienced. In contrast to 
semantic memory, then, "episodic memory affords the additional capability of acquisition and retention of knowledge about personally experienced events and their temporal relations in subjective time and the ability to mentally 'travel back' in time" (Tulving, 1985, p. 387). Despite the differences between the two systems, however, when people are asked to recall the presidents of the United States (presumably tapping semantic memory), one observes a conventional-looking $U$-shaped serial position function just like when people are asked to recall the list of words they have just heard (Roediger \& Crowder, 1976).

The presidential serial position function first reported by Roediger and Crowder (1976) has been replicated a number of times (e.g., Crowder, 1993; Healy, Havas, \& Parker, 2000; Healy \& Parker, 2001), and a similar function is also observed with Canadian prime ministers (Neath \& SaintAubin, 2011). A second class of stimuli has also been examined: Maylor (2002) demonstrated a conventionallooking serial position function when regular church goers ordered the verses in a well-known hymn, and Overstreet and Healy (2011) observed a serial position function when students at the University of Colorado ordered the lines of their alma mater's "fight song."

The question is whether these semantic serial position functions arise from the same fundamental principle as those observed in episodic memory tasks. There are a number of reasons why one might be reluctant to conclude that they are the same and arise from the same fundamental cause. First, one could argue that there are really only two examples of serial position functions in semantic memory, one that uses names of politicians and one that uses parts of songs. This is in stark contrast to the ubiquity of functions observed in episodic tasks.

Second, one could argue that each of these two classes of stimuli is problematic. For example, one problem with the presidential data concerns the frequency with which each item is encountered, and one alternate account could be differential exposure: Those presidents and prime ministers who receive the most exposure are those who are well recalled. This is different from the typical episodic case in which exposure to the to-be-recalled items is strictly controlled. One problem with the song data concerns whether the lyrics themselves convey order information. Although the hymn used by Maylor (2002) was chosen to minimize sequential cues, a control group of non-church-goers performed better than chance at reconstructing the order of the verses. Similarly, while Overstreet and Healy (2011) included a control group of students who professed not to know the lyrics, these students also performed better than chance.

Third, one could argue that a single account of both episodic and semantic serial position functions is automatically ruled out because there has to be at least two different accounts of serial position functions in episodic memory (e.g., Davelaar, Goshen-Gottstein, \& Ashkenazi, 2005). That is, different explanations of episodic serial position functions are needed to take into account when short-term memory plays a role (i.e., immediate recall) and when it does not (i.e., the continual distractor paradigm). While the specific points raised by Davelaar et al. have been addressed elsewhere (see Neath \& Brown, 2006), the larger point remains: Is it possible to have a single account that applies to all serial position functions, whatever the hypothetical underlying memory system might be? While it is not possible to prove that a single model does apply to all possible functions, it is possible to devise tests that could prove that a specific model cannot account for a particular set of data.

The purpose of the present study, then, was three fold: (1) increase the number of demonstrations of semantic serial position functions, (2) find song data that result in chance performance for those participants who indicate no familiarity with the lyrics, and (3) continue testing a unitary account of memory to see whether it can fit the new semantic serial position functions. Before describing the demonstrations, we first provide a brief overview of SIMPLE.

\section{SIMPLE}

SIMPLE (scale independent memory, perception, and learning) is a local relative distinctiveness model that was originally developed to explain serial position effects in standard episodic memory tasks, such as free recall of a list of words that were just seen (see Brown, Neath, \& Chater, 2007; Neath \& Brown, 2006). However, the model has also been fit to the serial position functions observed when the presidents of the United States (Neath, 2010), the prime ministers of Canada (Neath \& Saint-Aubin, 2011), and the verses of a hymn (Neath \& Brown, 2006) are recalled. In the description below, we focus only on those aspects of the model relevant to serial position functions; for a more complete account, see Brown et al., Neath and Brown, and Surprenant and Neath (2009, Chap. 8).

In SIMPLE, items are represented as points along a dimension (or in more complex situations, as points in multidimensional space). The particular dimension depends on the task. For example, in a typical episodic task, the experimenter has controlled so many aspects of the experiment and the stimuli that, usually, the only source of systematic variation concerns when the item was presented. In these situations, the data suggest that people use relative time of presentation as the dimension. However, if the experimenter makes time a less useful cue-by, for example, having variable and random durations between items, rather than a predictable temporal interval — people will use a different dimension, usually ordinal position. If the items vary along a perceptual dimension, such as frequency (i.e., 
Hertz) or length (i.e., $\mathrm{mm}$ ), people may use that dimension instead (see Neath, Brown, McCormack, Chater, \& Freeman, 2006).

It is assumed that physical magnitudes, including temporal values, undergo a log transformation (see Brown et al., 2007; Murdock, 1960; Neath et al., 2006). Because of this $\log$ transform, a steady rate of presentation (e.g., one item per second) results in recency items being spaced further apart and the earlier items being more closely spaced on the temporal dimension. Brown et al. termed this Weberian compression. The second factor that contributes to both primacy and recency is an edge effect: No items precede the first or follow the last items, and this lack of neighbors on one side conveys an additional benefit that middle items do not enjoy.

At the heart of the model is the idea that an item will be remembered to the extent that it is more distinct than close neighbors on the relevant dimension(s) at the time of test. The similarity between two memory representations $i$ and $j$, $\eta_{i, j}$, with values $M_{i}$ and $M_{j}$ on a psychological dimension, is given by Equation 1:

$\eta_{i, j}=e^{-c\left|M_{i}-M_{j}\right|}$

As in many models, it is assumed that similarity falls off as a decreasing function of the distance between two representations (e.g., Shepard, 1987). The main free parameter in SIMPLE is $c$ : With higher values of $c$, distant items become less similar and, thus, have less influence.

The probability of producing the response associated with item $i, R_{i}$, when given the cue for stimulus $j, C_{j}$, is given by Equation 2, in which $n$ is the number of items in the set:

$P\left(R_{i} \mid C_{j}\right)=\frac{\eta_{i, j}}{\sum_{k=1}^{n} \eta_{j, k}}$

For a reconstruction-of-order task, as used in the present work, omissions are not possible. All that needs to be done to fit data is to determine the most likely dimension being used, order the items on that dimension, and then calculate the recall probabilities. ${ }^{1}$

It is important to keep in mind the goal of SIMPLE: As Brown et al. (2007) noted, "our focus [with SIMPLE] is on capturing a range of qualitative effects across paradigms" (p. 545). One reason is because, as Hintzman (1991) noted, "in virtually every experimental situation, there are significant sources of variance that our models do not even attempt to capture" (p. 49). Given the combination of uncontrolled learning, uncontrolled stimuli, and only one free parameter

\footnotetext{
${ }^{1}$ Surprenant, Neath, and Brown (2006) show how multidimensional scaling can be used to more objectively determine the dimensions.
}

in the model, the focus is on the qualitative shape of the serial position function, the degree to which items are correctly placed in order, and when items are not placed in the correct position, the degree to which those items are placed in close positions.

When fitting the hymn data from Maylor (2002), it was assumed that only a single dimension, ordinal position, was used (for details, see Neath \& Brown, 2006). That is, the first verse was given a value of 1 , the second verse a value of 2 , and so on. Primacy and recency occur for the same fundamental reason as when there is immediate serial recall of a list of words from episodic memory: Weberian compression and edge effects. This results in some items being relatively more distinct at the time of retrieval than competing items.

To fit the presidential data, two dimensions were used. Healy et al. (2000) drew a distinction between item and order distinctiveness (for details, see Neath, 2010). The former corresponds to the idea that the presidents do differ, over and above any differences due to order, in terms of their importance and what is known about them. Because it is not entirely clear how to measure this particular dimension directly, a proxy measure was used. It was assumed that the number of Web pages returned by a search using Google would be related to both the amount known about that president and his importance. For the second dimension, order distinctiveness, the numbers $1,2,3$, and so on were used, but unlike in the case of the hymn data, the most recent president, rather than the first president, received the value 1 . The reason has to do with orientation: Neath and Crowder (1996) considered orientation - that is, whether the list subjectively begins at the beginning and goes to the end (i.e., currently, Washington would be 1 and Obama 44) or whether the most recent item is considered the first item and the other items recede in the distance (i.e., Obama 1 and Washington 44). Different factors may cause a person to adopt one orientation or the other, and we return to this issue in the General Discussion section. In the case of presidents and prime ministers, the rationale was that the current president's position changes more than earlier presidents' positions, receding from a very distinctive position of "current" to the less distinctive middle portion of the list. In the case of Maylor's (2002) hymn, verse 6 will always be the final verse; there will never be a verse 7 . In the case of presidents and prime ministers, the current one will eventually give way to a successor.

The way in which two-dimensional distinctiveness was calculated for the presidential data was identical to the way two-dimensional distinctiveness has been calculated in, for example, immediate serial recall (see Brown et al., 2007). Regardless of the number of dimensions, primacy and recency occur for the same fundamental reason: Recall is related to relative distinctiveness, which is determined by both edge effects and Weberian compression. 
According to SIMPLE, then, when the to-be-remembered items can be sensibly ordered along some dimension, a serial position function will be observed. The particular levels of primacy and recency will vary depending on the task - there is typically more recency in free recall and more primacy in serial recall tasks, for example - but the cause is fundamentally the same.

In the three demonstrations below, then, three sets of stimuli that can be sensibly ordered along a single dimension are tested, and SIMPLE is fit to each result.

\section{Demonstration 1}

In Demonstration 1, memory for the lyrics of theme songs of two children's cartoons-Pokémon and Scooby-Doo-was examined. These television theme songs were chosen because they were known to most of our participants, they were brief (16 lines; $\sim 1 \mathrm{~min}$ in duration, so participants typically would hear each song in its entirety), and participants were more likely (as compared with previous lyrical studies) to have learned them incidentally during their childhood. That is, unlike the Colorado fight song or a hymn for a regular churchgoer, there was likely no explicit requirement to ever produce (i.e., sing) the songs when they heard them. That said, we acknowledge that children sometimes will sing along with a theme song, so this is by no means a purely incidental task.

One challenge in using lyrical stimuli is that there tends to be either (1) a fair amount of repetition in the lyrics (e.g., repeated chorus, bridge, sentence, or phrase) or (2) a logical story structure to the lyrics; both are potentially problematic when the interest is in order retention. The Pokémon and Scooby-Doo theme songs were chosen after collecting familiarity ratings of 20 children's television theme songs from 24 college freshmen and then examining the repetition and story structure of the lyrics of the most familiar songs. Although Pokémon and Scooby-Doo scored relatively low on these measures, they still contained some repetition. To address this issue, we organized each song into couplets, as opposed to single lines, to ensure that each to-be-remembered couplet was unique and not repeated.

Participants in this study were asked first to rate their familiarity with 12 children's television shows and then rate their confidence in being able to recall the show's theme song. Following the rating task, participants were given two separate free reconstruction-of-order tasks in which the eight couplets of each song were shown in a random order on one side of a sheet of paper, and participants had to place the couplets into their appropriate serial order. They were asked to reorder all of the couplets, even if they had to guess.
Method

\section{Participants}

One hundred introductory psychology students from Lake Forest College participated for credit in their introduction to psychology course. Participants completed the study in two large groups of approximately 50 students in a classroom setting. Each session lasted approximately $15 \mathrm{~min}$.

\section{Design and materials}

The study consisted of two parts: (1) a familiarity- and confidence-rating task and (2) a pair of free reconstructionof-order tasks. In part 1, participants received a list of 12 titles of children- or family-oriented television programsincluding Scooby-Doo, Pokémon, Sesame Street, Duck Tales, Full House, among others-and instructions to provide three separate ratings for each show. All three ratings required a response on a $1-5$ scale, where $1=$ not at all familiar (or confident) and $5=$ very familiar (or confident). The three ratings were in response to the following questions: (1) How familiar are you with this show? (2) How confident are you that you could remember the theme song without hearing the melody? and (3) How confident are you that you could remember the theme song after hearing the melody? Three blank lines, one for each rating, were positioned next to each title.

In part 2, participants received two free reconstructionof-order tasks in which they were asked to reconstruct the lyrics from two of the previously rated shows-Scooby-Doo and Pokémon. Each theme song was organized into eight couplets, and these couplets were randomly reordered and paired with a letter $(\mathrm{A}-\mathrm{H})$. A column of numbers $(1-8)$ and blank lines appeared next to the column of couplets. These two theme songs were chosen primarily because of their manageable length, lack of a repeated chorus, and high familiarity and confidence ratings from the pilot study mentioned earlier. Although we attempted to minimize lyrical repetition, these theme songs still had some repetitive components; indeed, repetition appears to be a staple of this genre. The choice to organize the songs into couplets was designed to ensure that each to-be-reconstructed lyric was unique. For instance, the individual line "Scooby Dooby Doo, where are you?" appears twice in its song, but this line helped form two distinct couplets when "We need some help from you now" and "We've got some work to do now" were added, respectively.

\section{Procedure}

In each session, participants were given a packet that contained instructions, the rating task, and the reconstruction-of-order 
tasks. The study was self-paced and began with participants reading the instructions silently. In part 1 , participants were asked to make and record three separate ratings for each of 12 television shows. Next, participants read the instructions for part 2, which asked them to reorder the scrambled couplets by recording the letter of the first couplet $(\mathrm{A}-\mathrm{H})$ next to number 1 , the letter of second couplet with number 2, and so forth. Participants were asked to fill in all the blanks, even if they had to guess. All participants received identical packets with the same shows and couplets in the same random order. Upon completion of the second reconstruction-of-order task, participants were debriefed and thanked for their participation.

\section{Results and discussion}

Table 1 gives the proportion of couplets correctly reconstructed in order as a function of familiarity rating. As can be seen, the higher the rated familiarity, the more accurate the overall performance. One concern is whether the order of the couplets is discernible just from the lyrics themselves. That is, how accurately can the order of the couplets be reconstructed by people who indicate no knowledge of the songs? To assess this, we first examined the data from the 45 participants who gave a rating of 1 (not at all familiar) to either Scooby-Doo or Pokémon. The mean proportion of couplets correctly reconstructed in order was .103 , which is not different from chance performance of $.125, t(44)=$ $-1.091, p>.25$. A one-way repeated measures analysis of variance, with only serial position as a factor, yielded no effect of serial position, $F(7,308)=1.515, M S E=0.084$, partial $\eta^{2}=.033, p>.15$. Therefore, there is no support for the claim that these lyrics contain useful information about the order of the couplets.

The data from the participants who gave ratings of 2 or higher were used for the remaining analyses, and the mean proportion of couplets reconstructed in each possible serial position is shown in Fig. 1. The open circles are the data, and the lines represent a fit of SIMPLE (see below). In this position error gradient, the "peaks" show correct performance (e.g., couplet 1 was correctly reconstructed as being in the first position approximately $60 \%$ of the time, couplet

Table 1 Familiarity rating $(1=$ not at all familiar; $5=$ very familiar $)$, proportion of couplets correctly reconstructed, and number of participants giving that rating for Demonstration 1

\begin{tabular}{lcc}
\hline Rating & Performance & $N$ \\
\hline 1 & 0.103 & 45 \\
2 & 0.273 & 22 \\
3 & 0.304 & 23 \\
4 & 0.314 & 43 \\
5 & 0.457 & 67 \\
\hline
\end{tabular}

2 was correctly reconstructed as being in the second position approximately $44 \%$ of the time, and so on), and the remaining points are all errors (e.g., couplet 1 was incorrectly reconstructed as being in the second position approximately $24 \%$ of the time). The typical bow-shaped serial position function can be seen by connecting the peaks in each panel. As is clearly evident, there is a primacy effect, a recency effect, and worse performance for mid-list items. A one-way repeated measures analysis of variance on the proportion of couplets correctly reconstructed, with only serial position as a factor, yielded a significant effect of serial position, $F(7$, $1078)=20.116, M S E=0.132$, partial $\eta^{2}=.116, p<.001$.

SIMPLE was fit to the data using the same approach as that used to fit the data reported by Maylor (2002), described above. We assumed that the dimension used by the participants was ordinal position, such that couplet 1 had a value of 1 and couplet 8 had a value of 8 . The sole free parameter in the model is $c$. Figure 1 shows the predictions of SIMPLE with $c=1.85$. As is readily apparent, the model gave a reasonable fit for all of the couplets except for the final one: Overall, $r^{2}=.780$, but with couplet 8 excluded, $r^{2}$ $=.904$. For couplets $1-7$, the couplet was most likely to be placed in the correct position, and then errors are related to distance: For example, couplet 5 is most likely to be placed in position 5; then, when an error is made, it is most likely to be placed in positions 4 and 6 and least likely in position 1 . This pattern was observed both by Maylor and Overstreet and Healy (2011) in their semantic serial position functions, and the pattern is also typical of episodic data (see Brown et al., 2007). In contrast, couplet 8 was more likely to be recalled in position 1 than in position 2 , more likely to be recalled in position 2 than in position 3, and so on. SIMPLE predicts that these should be reversed.

One possibility for this anomalous effect is that there is something unusual about the specific stimuli used. Indeed, one of the reasons for this line of research is to broaden the number of stimulus sets tested so that uncontrolled or idiosyncratic properties can be identified. The results of couplet 8 are not what was expected both according to the available data and according to SIMPLE. Additional studies using different lyrics should reveal whether couplet 8 is an anomaly due to these specific stimuli or whether, when more stimulus sets are tested, SIMPLE's predictions become increasingly inaccurate.

There are three important results from Demonstration 1. First, people who indicated no familiarity with the lyrics to the theme songs for the Scooby-Doo and Pokémon television shows had levels of performance that did not differ from chance, suggesting that the lyrics themselves offered no useful information about order. Second, for those people with at least some minimal level of familiarity with the lyrics, remembering those lyrics yielded a serial position function with characteristic primacy and recency effects. 
Fig. 1 Proportion of times cartoon theme song couplets were remembered as occurring in each possible serial position in a free reconstruction-of-order task. The open circles are the data, and the lines represent a fit of SIMPLE
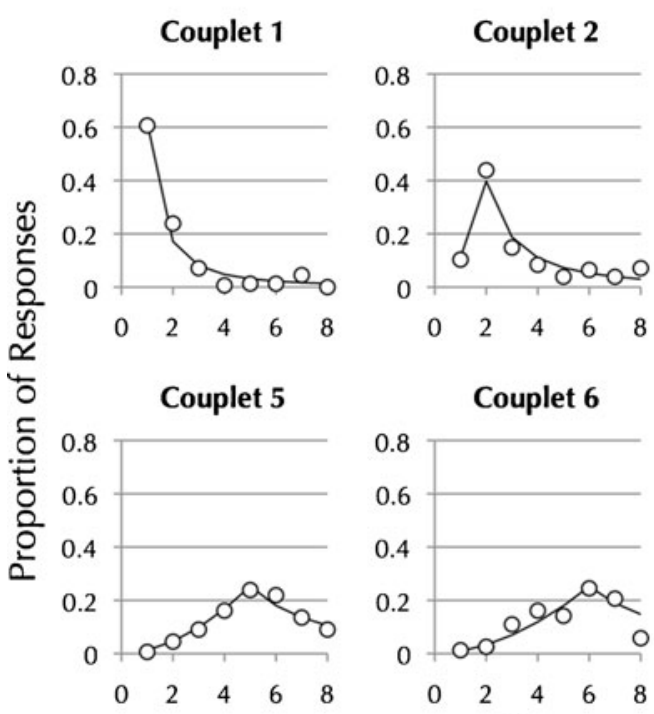

Couplet 6
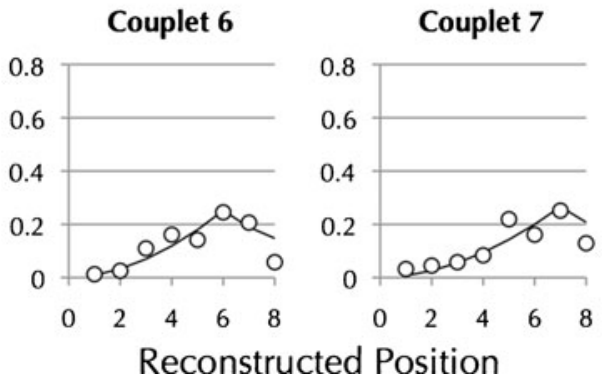

Couplet 3
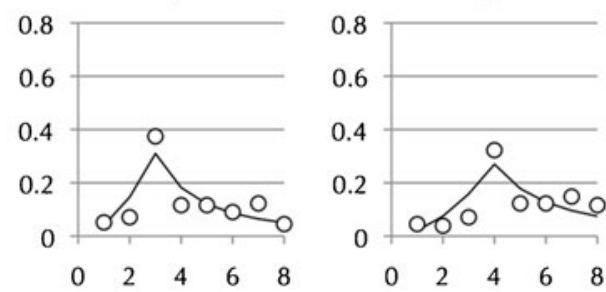

Couplet 8

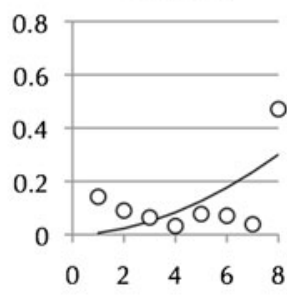

When a particular couplet was recalled in an incorrect position, it was most likely recalled in a position adjacent to the correct position. Thus, both accurate responses and error data mimic those observed in episodic settings. In this respect, the data replicate the findings of Maylor (2002) and Overstreet and Healy (2011). One advantage of now having three serial position functions using three different sets of lyrics is that it reduces the likelihood that the general pattern is due to some stimulus-specific factor. Third, SIMPLE fit the data quite accurately, considering that it has only a single free parameter.

Nonetheless, one might object that all demonstrations of serial position functions that are thought to tap semantic memory still use either political figures or lyrics. Demonstrations 2 and 3 were designed to double the number of the stimulus classes.

\section{Demonstrations 2 and 3}

Demonstrations 2 and 3 explored whether semantic serial position functions are obtained with two new types of stimuli: Remembering the release order of books in a popular series (Demonstration 2) and remembering the order of films (Demonstration 3). These stimuli were chosen because they were released within the lifetimes of the participants, they were highly popular and familiar to the participants, and the desired order information was not likely to have been intentionally or explicitly learned. In addition, Demonstrations 2 and 3 used single items as the stimuli, rather than couplets. While there may not be an issue with using couplets or verses as stimuli, using only single items is more akin to standard studies of episodic memory.
Participants first were asked to rate their familiarity with each book and film (from never heard of it to read/seen multiple times). Following the rating task, participants were given three separate free reconstruction-of-order tasks - one for the books and one each for two sets of movies - in which the stimuli were shown in a random order on one side of a sheet of paper and participants had to place them in their appropriate release order (from oldest to most recent). They were asked to reorder all of the stimuli, even if they had to guess. The data were collected at the same time from the same participants, and therefore, the methodology for both is described together, but the data are reported separately.

\section{Method}

\section{Participants}

Ninety different introductory psychology students from Lake Forest College participated for credit in their introduction to psychology course. Participants completed the study in groups of approximately 10 students in a classroom setting. Each session lasted approximately $15 \mathrm{~min}$.

\section{Design and materials}

The study consisted of two parts: (1) a familiarity-rating task, and (2) three free reconstruction-of-order tasks. In part 1, participants received a list of 7 book and 18 film titles, as well as instructions to provide a familiarity rating for each book/ film on a 1-5 scale, where 1 = I've never heard of this book/ film; 2 = I've heard of this book/film, but I have no other knowledge of it; 3 = I've heard of this book/film and have some knowledge of it, but I haven't read/seen it; 4 = I've read/seen 
this book/film once; and $5=$ I've read/seen this book/film multiple times.

The books were the seven titles in the Harry Potter series. U.S. titles were used (i.e., we used Harry Potter and the Sorcerer's Stone rather than Harry Potter and the Philosopher's Stone). Two sets of films were used. The first set consisted of nine movies from Pixar (e.g., Toy Story, A Bug's Life, Monsters Inc., etc.), and the second set consisted of the nine top-grossing movies from 2002 to 2010 (e.g., Iron Man, Pirates of the Caribbean, Avatar, etc.; one from each year). For both sets of films, the first movie in a franchise was included (e.g., Toy Story), but any sequels were not (e.g., Toy Story 2). When the top-grossing film was a sequel or a Pixar film, we chose the next highest grossing non-Pixar nonsequel on the list. In the end, all of the "top-grossing" films in this study exceed revenue of $\$ 500$ million worldwide and $\$ 180$ million in the United States (all revenue in U.S. dollars).

In part 2, participants received three separate free reconstruction-of-order tasks in which they were asked to reconstruct the original order of release for the books and for the two sets of films. Each book or film was randomly reordered and paired with a letter (A-I or A-G, respectively). For the top-grossing movies, a column of years (20022010) and blank lines appeared next to the column of films. For the Pixar films and Harry Potter books, the numbers 1-9 and 1-7 appeared next to the blank lines, respectively.

\section{Procedure}

In each session, participants were given a packet that contained instructions, the rating task, and the reconstruction-of-order tasks. The study was self-paced and began with participants reading the instructions silently. In part 1, participants were asked to make and record one familiarity rating for each of seven books and 18 films. Next, participants read the instructions for part 2, which asked them to reorder the scrambled books and films according to their original order of release. Participants were asked to fill in all the blanks, even if they had to guess. All participants received identical packets with the same books and films in the same random order. Upon completion of the third reconstruction-of-order task, participants were debriefed and thanked for their participation.

\section{Demonstration 2 results and discussion}

All 90 participants gave a rating of 2 (I've heard of this film/ book, but I have no other knowledge of it) or higher for the Harry Potter books, and 76 gave a rating that indicated that they had some knowledge (i.e., a rating of 3 ) or that they had actually read the books (i.e., a rating of 4 or 5). Overall, the mean rating was 3.617, with a standard deviation of 0.972 .

The mean proportion of books reconstructed in each possible serial position for the 76 participants who rated their familiarity as 3 or higher is shown in Fig. 2. The open circles are the data, and the lines represent a fit of SIMPLE (see below). As in Demonstration 1, there is a primacy effect, a recency effect, and worse performance for mid-list items. A one-way repeated measures analysis of variance on the proportion of books correctly reconstructed in order, with only serial position as a factor, yielded a significant effect of serial position, $F(6,450)=4.287$, $M S E=0.110$, partial $\eta^{2}=.054, p<.001$.

SIMPLE was fit to the data in the same way as in Demonstration 1. The dimension used was ordinal position, and there was only one free parameter, $c$. With $c=6$, the model gave a good fit, with $r^{2}=.964$. The main divergence of the model from the data was a slight overestimate of performance, especially at the early serial positions. However, with only one free parameter and 49 data points to fit, the model accounts well for the data.

One might question whether this was really a test of semantic memory. Consider a person who has read all of the Harry Potter books. Most likely, that person can recall some episodic information, such as book 1 was read while traveling to London. One way of addressing this issue is to examine the data from those who had not read the books (i.e., gave a rating of 2 or $3, n=52$ ) but who had heard of the books and had some knowledge of them. It is unlikely that these participants could have had the same episodic information available as those who had read the book, and therefore, it is more difficult to claim that these participants might have been using episodic memory rather than semantic memory. When we fit SIMPLE to these data, keeping $c=6, r^{2}=.940$. There was a conventional-looking serial position function, with primacy and recency effects. A oneway repeated measures analysis of variance on the proportion of books correctly reconstructed in order, with only serial position as a factor, yielded a significant effect of serial position, $F(6,50)=3.437, M S E=0.146$, partial $\eta^{2}=.064, p<.01$.

Demonstration 2 found that yet another kind of stimulus, book titles, yields a conventional-looking serial position function: Recalling the order in which a series of books was published results in primacy and recency effects, with worse recall of mid-series items. In addition, when an error was made, the book was most likely to be recalled in an adjacent position. Once again, SIMPLE fit the data well, considering it has just one free parameter.

There may be problems with using books as stimuli, but such problems are likely to be different from those associated with recalling political figures or song lyrics. Even so, Demonstration 3 used yet another kind of stimulus, films, as described in the Method section above.

\section{Demonstration 3 results and discussion}

The participants in this demonstration were even more familiar with the films than with the Harry Potter books. For each participant, a mean rating for each of the two sets of 
Fig. 2 Proportion of times each Harry Potter book was remembered as occurring in each possible serial position in a free reconstruction-of-order task. The open circles are the data, and the lines represent a fit of SIMPLE. HP1 indicates the first Harry Potter book, HP2 indicates the second Harry Potter book, and so on
O Data - Model

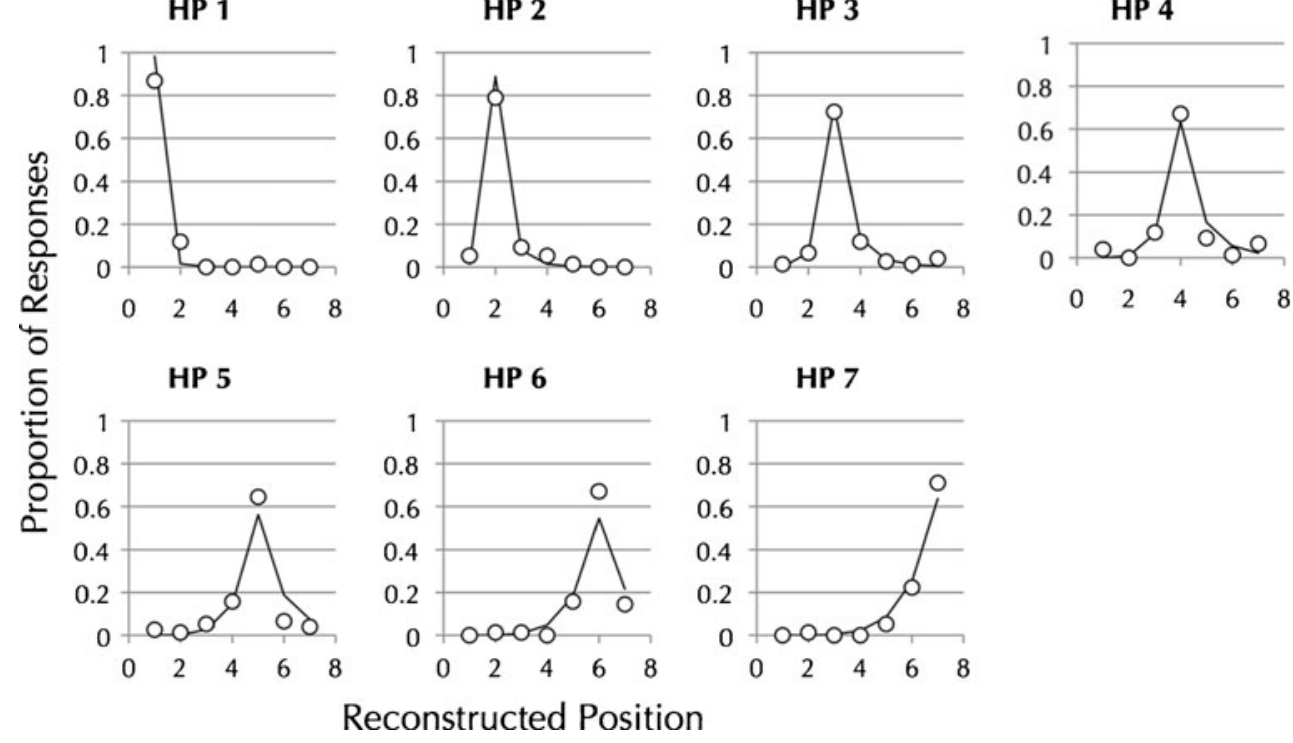

nine films was computed. For the top-grossing movies, the mean overall rating was 3.811 , with a standard deviation of 0.503; for the Pixar movies, the mean overall rating was 4.169 , with a standard deviation of 0.560 . Only 4 participants gave a rating below 3 for the top-grossing movies, and only 5 gave a rating below 3 for the Pixar movies. The data from these 9 participants were not included in the analyses below, unless otherwise explicitly stated.

The mean proportion of movies reconstructed in each possible serial position for the participants who rated their familiarity as 3 or higher is shown in Fig. 3. The open circles are the data, and the lines represent a fit of SIMPLE (see below). As in Demonstrations 1 and 2, there is a primacy effect, a recency effect, and worse performance for mid-list items. A one-way repeated measures analysis of variance on the proportion of movies correctly reconstructed in order, with only serial position as a factor, yielded a significant effect of serial position, $F(8,1360)=16.841, M S E=0.188$, partial $\eta^{2}=.090, p<.001$.

To fit SIMPLE, only one change was made from the previous two fits. For Demonstrations 1 and 2, there is a natural, finite sequence in which the items line up along the

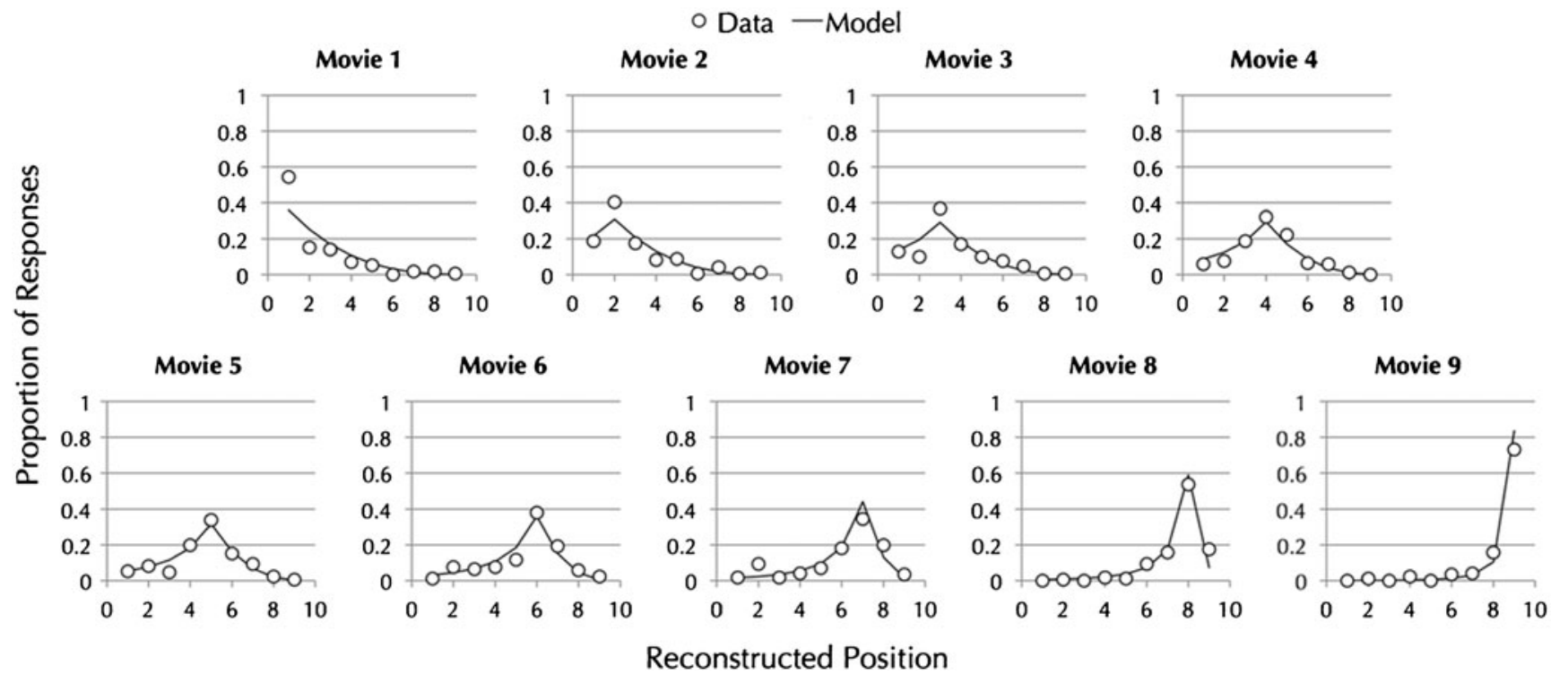

Fig. 3 Proportion of times each movie was remembered as occurring in each possible serial position in a free reconstruction-of-order task. The open circles are the data, and the lines represent a fit of SIMPLE.
Movie 1 indicates both the first Pixar movie and the top -grossing movie for 2002; Movie 2 indicates both the second Pixar movie and the top-grossing movie for 2003 
order dimension; that is, there is a clear and unambiguous first couplet to the theme song, and a clear and unambiguous first book in the Harry Potter series. In contrast, the set of movies form a more heterogeneous group, and the range is somewhat arbitrary. Unlike verses in a hymn or lines in a song, the final item is only temporarily a final item; put another way, the last item is last only due to the particular grouping used. In this respect, the movies are more like the presidential data: The most recent president will, at some point, become the penultimate president. For both movies and presidents, then, recall seems more like that in a typical episodic task. When free recall is modeled with SIMPLE, the zero point is the time of recall, and as items recede into the past, the values increase (see Chap. 8 of Surprenant $\&$ Neath, 2009, for a detailed example, and Neath, 2010, and Neath \& Crowder, 1996, for a discussion). Thus, to fit the movie data, the most recent movie was given a value of 1 and the oldest movie was given a value of 9 on the order dimension. With this change, and with the single free parameter $c=3$, SIMPLE gave a reasonable fit of the data, $r^{2}=.905$.

As with the data from Demonstration 2, we address the issue of whether participants were really using semantic memory by looking at the data for those participants who gave a rating of 2 or $3(n=74)$. As with Demonstration 2, a conventional-looking serial position effect, with primacy and recency effects, was apparent. A one-way analysis of variance with only serial position as a factor yielded a significant effect of serial position, $F(8,73)=9.192, M S E=0.179$, partial $\eta^{2}=.112, p<.001$. One difference from Demonstration 2 is that the fit of the model to the subset of data was reduced: With $c$ kept at $3, r^{2}$ was reduced to .826 . One reason for the decrease in the fit in this subset of data is that accuracy in recalling the order of the fourth movie (.338) was higher than than for either the third (.216) or the fifth (.230). Despite this worse fit, participants who were unlikely to have episodic information about the films nonetheless produced serial position functions with primacy and recency effects.

As with recall of the order of books and the order of theme song lyrics, recall of a set of movies yields a conventional-looking serial position function, with position error gradients reminiscent of those observed in episodic tasks. Recall of the order of a somewhat arbitrary set of movies may be problematic in some respects, but those issues are likely to be different from those associated with a finite set of books, and the problems are likely to be different from those associated with recall of political figures or with lyrics in a song. There are now four different types of stimuli that result in semantic serial position functions, and as is shown in Demonstrations 1-3, in Neath (2010), in Neath and Saint-Aubin (2011), and in Neath and Brown (2006), all such functions can be fit by SIMPLE.

\section{General discussion}

Are the serial position functions observed when items that are presumably in semantic memory are recalled the same as those observed when items that are presumably in episodic memory are recalled? Put another way, can a single account explain serial position functions obtained in both episodic and semantic memory? We suggest that currently, the best answer to each of these questions is "yes."

In this article, we report three new semantic serial position functions, and we also double the number of different types of stimuli that produce such functions. Serial position functions are observable not only with recall of political figures and song lyrics, but also with recall of the order of series of books and recall of the order of movies. While there may be factors associated with each type of stimulus that could be questioned, the more instances there are of serial position functions in tasks tapping semantic memory, the less important is any one particular objection to any one particular kind of stimulus.

One difficulty in examining serial position functions in semantic memory is the lack of control over many aspects of the stimuli and the learning episode. Although the theme song lyrics in Demonstration 1 achieved the main goal of not conveying order information, some aspect of couplet 8 seems to have resulted in an unexpected pattern (unexpected on the basis of past empirical results and in terms of theoretical predictions). Similarly, the movie stimuli in Demonstration 3 yielded conventional-looking serial position functions, but when only the data from those participants who gave a rating of 2 or 3 were examined, performance on movie 4 was unexpectedly higher than that for movie 3 or movie 5 . This pattern was not seen in the full data set. One goal of the present work was to provide more examples so that the likely importance of each of these deviations could be assessed. The logic is that while each set of stimuli may have its own idiosyncrasies (e.g., Lincoln in the presidential data; Macdonald in the prime ministerial data; conveyance of order information in the hymn data; couplet 8 in the cartoon lyric data; and the fourth movie in a subset of the movie data), the larger body of data reveals more clearly what is repeatedly observed: primacy and recency effects. With only one set of stimuli, an objection to a problem with a stimulus set is potentially critically important. With multiple sets of stimuli, each of which produce the main result of interest but each of which has a different type of deviation, the objections become far less relevant to the larger issue.

SIMPLE fit the data from all three demonstrations, despite having only a single free parameter, $c$. This parameter was allowed to vary freely, and presently we refrain from speculating on the relationship between the value of $c$ and the particular demonstration, because so many things differ 
between the stimulus sets. As in past demonstrations, sometimes a forward orientation was used (i.e., the first item was given a value of 1), and sometimes a backward orientation was used (i.e., the last item was given a value of 1). As more stimulus sets are examined, it may be possible to give a more principled account of when people will adopt each orientation. A tentative account notes that for "complete" sets (i.e., there will never be a seventh verse added to a six-verse hymn; there will never be an additional couplet added to the theme to Scooby-Doo; there will never be an eighth Harry Potter book), the forward orientation gives a better fit but that, for "incomplete" sets, where there will be additional items in the future (i.e., there will be a new president; there will be a new prime minister; there will be new movies), a backward orientation gives a better fit. The rationale is that a change from current to past is psychologically large, and to reflect this, the item goes from 1 to 2 and so on. Again, the more stimulus sets that are tested, the more clear it will be whether the rationale proposed for adopting a forward or a backward perspective is reasonable.

One final issue concerns the extent to which the three demonstrations reported here tap semantic memory, as opposed to other memory systems (e.g., episodic). Our focus is on the key distinction between the two systems as described by proponents of the multiple-systems view: Was there, in addition to the information itself, information about the learning episode? We suspect that most researchers would agree that the political figures and lyric stimuli are least susceptible to this criticism, but the book and movie stimuli may be more problematic. We examined this by looking at the performance of those participants who were familiar with the books/movies but who had not read the books/movies. The idea is that whereas a participant who had read the books might be able to remember that he or she had read one book in London and, therefore, that book must have come out after some other book he or she had read in Rome, those participants who had not read the book are less likely to have such episodic information available. The participants who gave the lowest familiarity ratings still produced conventional-looking serial position functions. For researchers who still doubt whether the two new demonstrations are of semantic memory, the issue can be readily resolved by an experiment: In addition to familiarity ratings, the experimenter could include a measure of the presence of episodic information. Our prediction is that conventional-looking serial position functions will be observed regardless of whether the data indicate that episodic memory was used, whereas the prediction of theorists who believe that serial position functions do not arise in semantic memory tasks predict that conventional-looking serial position functions will be observable only when there is episodic information also available. ${ }^{2}$

\footnotetext{
${ }^{2}$ We note that this leaves unexplained the presence of serial position functions observed with politicians and lyrics as stimuli.
}

SIMPLE offers the same explanation for the three functions found here, for those observed with presidents (Roediger \& Crowder 1976), prime ministers (Neath \& Saint-Aubin, 2011), and hymn verses (Maylor, 2002; Overstreet \& Healy, 2011), and for those found in episodic memory: Items are well remembered to the extent that they are more distinct than their close neighbors at the time of test.

Serial position functions arise when items are ordered along one or more dimensions, but the particular dimension(s) can vary (see Neath \& Saint-Aubin, 2011). For example, in episodic tasks, the dimension is usually temporal (i.e., relative time) but need not be; items can be ordered along perceptual dimensions (Neath et al., 2006), a position dimension (Surprenant et al., 2006), or any other dimension that is useful. In semantic tasks, the ordering is less likely to be temporally based and more likely to be a nominal or logical ordering. That is, the second verse follows the first verse. Time per se is not a factor. If stimuli are not ordered along one or more dimensions, serial position functions will not be observed. For example, serial position functions should not be observed when different breeds of dogs or the names of the 10 Canadian provinces are recalled but will be when the Canadian prime ministers are recalled. Similarly, whereas recalling the order of Disney films should produce such a serial position function, recalling the names of the seven dwarves in the Disney film should not (see Meyer \& Hilterbrand, 1984).

We suggest that, given the above, the debate has changed. Until recently, it seemed necessary to demonstrate that serial position functions observed in semantic memory were similar to those observed in episodic memory. Given the increase in the number of different stimuli that produce such functions, the replicability of the functions, and the ability of SIMPLE to fit the functions, we think that the evidence available currently suggests that serial position functions observed when items that are presumably in semantic memory are recalled arise because of the same processing as those observed when items that are presumably in episodic memory are recalled. It is not possible, of course, to test all possible situations in which serial positions might arise; nonetheless, there is a strong test of our claim: A multimemory systems proponent who thinks that serial position functions in semantic memory are fundamentally different from those in episodic memory need only show one example of a meaningful difference, and our claim is compromised.

Author note This research was supported, in part, by grants from NSERC to I.N. and A.M.S. Portions of this work were presented at the 53rd Annual Meeting of the Psychonomic Society, Minneapolis, November 2012. The authors thank Ada Sandoval for her help in the pilot process. 


\section{References}

Brown, G. D. A., Neath, I., \& Chater, N. (2007). A temporal ratio model of memory. Psychological Review, 114, 539-576.

Crowder, R. G. (1993). Short-term memory: Where do we stand? Memory \& Cognition, 21, 142-145.

Davelaar, E. J., Goshen-Gottstein, Y., \& Ashkenazi, A. (2005). The demise of short-term memory revisited: Empirical and computational investigations of recency effects. Psychological Review, 112, 3-42.

Healy, A. F., Havas, D. A., \& Parker, J. T. (2000). Comparing serial position effects in semantic and episodic memory using reconstruction of order tasks. Journal of Memory and Language, 42, 147-167.

Healy, A. F., \& Parker, J. T. (2001). Serial position effects in semantic memory: Reconstruction the order of U.S. Presidents and vicepresidents. In H. L. Roediger, J. S. Nairne, I. Neath, \& A. Surprenant (Eds.), The nature of remembering: Essays in honor of Robert G. Crowder (pp. 171-188). Washington, DC: American Psychological Association.

Hintzman, D. L. (1991). Why are formal models useful in psychology? In W. E. Hockley \& S. Lewandowsky (Eds.), Relating theory and data: Essays in honor of Bennet B. Murdock (pp. 39-56). Hillsdale, NJ: Erlbaum.

Maylor, E. A. (2002). Serial position effects in semantic memory: Reconstructing the order of verses of hymns. Psychonomic Bulletin \& Review, 9, 816-820.

Meyer, G. E., \& Hilterbrand, K. (1984). Does it pay to be "Bashful"? The Seven Dwarfs and long-term memory. The American Journal of Psychology, 97, 47-55.

Murdock, B. B., Jr. (1960). The distinctiveness of stimuli. Psychological Review, 67, 16-31.

Neath, I. (2010). Evidence for similar principles in episodic and semantic memory: The presidential serial position function. Memory \& Cognition, 38, 659-666.

Neath, I., \& Brown, G. D. A. (2006). SIMPLE: Further applications of a local distinctiveness model of memory. In B. H. Ross (Ed.), The psychology of learning and motivation (pp. 201-243). San Diego, CA: Academic Press.
Neath, I., Brown, G. D. A., McCormack, T., Chater, N., \& Freeman, R. (2006). Distinctiveness models of memory and absolute identification: Evidence for local, not global, effects. Quarterly Journal of Experimental Psychology, 59, 121-135.

Neath, I., \& Crowder, R. G. (1996). Distinctiveness and very shortterm serial position effects. Memory, 4, 225-242.

Neath, I., \& Saint-Aubin, J. (2011). Further evidence that similar principles govern recall from episodic and semantic memory: The Canadian prime ministerial serial position function. Canadian Journal of Experimental Psychology, 65, 77-83.

Overstreet, M. F., \& Healy, A. F. (2011). Item and order retention in semantic memory: Students' retention of the "CU fight song" lyrics. Memory \& Cognition, 39, 251-259.

Roediger, H. L., III, \& Crowder, R. G. (1976). A serial position effect in recall of United States presidents. Bulletin of the Psychonomic Society, 8, 275-278.

Schacter, D. L., Wagner, A. D., \& Buckner, R. L. (2000). Memory systems of 1999. In E. Tulving \& F. I. M. Craik (Eds.), The Oxford handbook of memory (pp. 627-643). New York: Oxford.

Sehulster, J. R. (1989). Content and temporal structure of autobiographical knowledge. Remembering twenty-five seasons at the Metropolitan Opera. Memory \& Cognition, 17, 590-606.

Shepard, R. N. (1987). Toward a universal law of generalization for psychological science. Science, 237, 1317-1323.

Surprenant, A. M., \& Neath, I. (2009). Principles of memory. New York: Psychology Press.

Surprenant, A. M., Neath, I., \& Brown, G. D. A. (2006). Modeling age-related differences in immediate memory using SIMPLE. Journal of Memory and Language, 55, 572-586.

Tulving, E. (1972). Episodic and semantic memory. In E. Tulving \& W. Donaldson (Eds.), Organization of memory (pp. 381-403). New York: Academic Press.

Tulving, E. (1983). Elements of episodic memory. Oxford: New York.

Tulving, E. (1985). How many memory systems are there? American Psychologist, 40, 385-398.

Wang, S.-H., \& Morris, G. M. (2010). Hippocampal-neocortical interactions in memory formation, consolidation, and reconsolidation. Annual Review of Psychology, 61, 49-79. 